\title{
Experimental investigation of the energy absorption capability of bonded crash boxes
}

\author{
L. Peroni \& M. Avalle \\ Department of Mechanics, \\ Politecnico di Torino (Technical University of Turin), Italy
}

\begin{abstract}
In the design of vehicle structures for crashworthiness there is a need for rigid subsystems that guarantee an undeformable survival cell for the passengers and deformable subsystems able to efficiently dissipate the kinetic energy. The front rail is the main deformable component dissipating energy in a frontal impact, which is the most dangerous crash situation. In frontal impact these rails have the greatest influence on vehicle crash performance. The design of the front rail, usually consisting of a thin walled prismatic column, requires definition of the geometry, that is, of the shape and dimensions of the cross section, of the thickness of the material, and of the material itself. In this work the analysis of the effect of different cross sections of the front rail and of the joining system is carried out. Furthermore, the collapse during crash is influenced by the loading rate since the loading speed has substantial influence on the mode of collapse and on the material behaviour. In fact, the structural materials used in this application are known to be strain-rate sensitive. Within the work, different types of sections are compared. The ground-breaking joining technology of bonding is examined: three different types of adhesive are compared, an acrylic, a one component epoxy and a two component epoxy. Adhesives can be used as a substitute to the widely used spot-welding to improve the structure performance mainly because of the continuous joint. The effects of the loading speed are taken into account by comparing quasi-static crush tests with dynamic impact tests. Dynamic tests have been performed under a drop tower testing apparatus built within the Vercelli campus of the II Faculty of Engineering of the Politecnico di Torino.
\end{abstract}

Keywords: bonded structures, adhesive bonding, energy absorbing components. 


\section{Introduction}

A very important issue in car design nowadays, is the trend in using new, smart materials. In the next future well known and widely used materials like deepdrawing steels will be discarded in favour of high-strength steels (dual-phase, TRIP steels etc.), aluminium alloys, magnesium alloys and various grades of polymeric materials and composites [1-2]. The reasons for this are many: the weight reduction to allow for more accessories and safety components, the strengthening of the structure and, last but not least, the cost reduction since even the low priced common steels suffered great costs rise due to increased demand from emerging countries.

Many problems are linked to the introduction of new materials: their properties are still not completely known, usually adopted technologies sometimes fail, and new environmental and protection problems can arise. One of the additional problems regards joining systems. For several years car body assembly was fully dominated by spot-welding. Resistance spot-welding is a very cheap and affordable technology to join steel sheets. It is highly customizable, can be extremely automated, is very quick, and does not require preparation of the parts prior joining. However, there are also some drawbacks: as in all the welding systems there is a heat affected zone that can affect the material strength, it is a spot connection system that causes high stress concentrations near the spot, and cannot be used to join different materials (unless very difficult procedures are adopted, whenever possible).

The most promising joining solution when dealing with different materials is bonding. The use of structural adhesives in car body construction has a lot of advantages: the joint is not localized in small areas eliminating stress concentrations, the adhesive layer can perform as insulating, protecting and damping material, it is possible to join different materials of almost any kind.

The main problem in using adhesives is their relatively low peel strength. However, up to date structural adhesives have gained very high peel strength sufficient to guarantee very robust designs. Probably the main concern in using adhesives, as for many polymer materials, relates to long term endurance, which is still not completely known, especially in severe environments.

Many other, supposed, drawbacks can be worked around by using state-ofthe-art knowledge on adhesive joints construction. Surface preparation is not necessary anymore: modern structural adhesives can be applied directly on raw surfaces, even dirty and oily. The long curing time can still pose some problems, but, using bonded joint together with other mechanical fastening methods or with provisional fasteners [3], this can be effectively solved: the usual oven treatment for car body paints is then exploited for adhesive polymerization too, if necessary.

Probably the greatest limit is cultural: designers and manufacturers are worried by the necessity to introduce too big modifications in components design to be suitable for bonding, as it was necessary in the past [4]. As will be shown in the present paper, this is not of concern since recent structural adhesives have so excellent properties to be able to overcome most possible inconvenient. 
Some results on the use of structural adhesives in structures subjected to crash will be shown in this paper. Comparison with traditional methods and the structural improvements have already been demonstrated [4-6] and will not be addressed here. Instead, comparison between different design and different adhesives will be illustrated.

The obtained results make obvious that many very effective possible solutions with adhesives are possible, and very convenient.

\section{Materials and adhesives}

The work addresses the characterization of crash columns subjected to axial compression and impact. Simple square section boxes made of steel sheet were considered to this purpose. The crash box columns were built by joining two half-shells obtained by plastic deformation. The material was a common DC04 steel for deep drawing constructions. Selection of this material was justified by many considerations: the availability of previous results with the same material [5-9] to allow for comparisons, the still relatively widespread use of this steel in car body constructions and, last but not least, accessibility and low cost of this material.

After a selection phase, taking into consideration previous experiences [5-6, 10] made with various kinds of adhesives, including Araldite $\AA$ and Loctite $\AA$ 9466, two types of adhesives were chosen:

- a urethane metacrylate ester, Loctite ${ }^{\circledR} 330$ Multibond

- $\quad$ an epoxy resin, Loctite Hysol® 9514

The acrylic ester 330 Multibond is a general purpose structural adhesive with good characteristics. Differently from traditional acrylic adhesives it has a much greater toughness that makes it useful for energy absorbing applications. Nominal shear strength according to ASTM D1002 is $15 \div 30 \mathrm{MPa}$, whereas tensile peel strength (DIN 53288) is $12 \div 22 \mathrm{MPa}$. Main limitation of this adhesive is the low temperature applicability: since it is for curing at ambient temperature, maximum operational temperature is relatively low $\left(120^{\circ} \mathrm{C}\right.$, but with progressive loss of strength already from $60^{\circ} \mathrm{C}$ ).

The Hysol 9514 epoxy is a high performance structural adhesive. Shear strength can be up to $45 \mathrm{MPa}$ (depending on adherends), with a peel strength of 9 $\mathrm{MPa}$. Temperature limit is quite high: strength reduction is important only above $120^{\circ} \mathrm{C}$. It has superior performance with respect to Hysol 9466 that was initially considered.

\section{Characterization of the strength of the adhesives}

A series of preliminary tests on the used adhesives were performed to measure the strength obtained with the specific sheet material. Shear strength single-lap tests according to ASTM D1002-94 standard, and T-peel strength tests according to ASTM D1876-95, were performed. Results of these tests are summarised in table 1. Results of the Hysol 9466 are also reported. Some shear tests were not 
performed according to ASTM standard, because the strength of the adhesive was in excess of the strength of the steel. In this case a specimen with only 250 $\mathrm{mm}^{2}$ bonded area, instead of $625 \mathrm{~mm}^{2}$, was used $(25 \mathrm{~mm}$ wide, $10 \mathrm{~mm}$ superposition length; the bonded pieces were 1.5 thick, $50 \mathrm{~mm}$ long).

Table 1: $\quad$ Strength of the used adhesives.

\begin{tabular}{ccc}
\hline Adhesive & $\begin{array}{c}\text { Shear strength, MPa } \\
\text { (ASTM D1002-94) }\end{array}$ & $\begin{array}{c}\text { Peel strength , kN } \\
\text { (ASTM D1876-95) }\end{array}$ \\
\hline Loctite $\AA$ 330 Multibond & $16 \div 22$ & $1.1 \div 1.2$ \\
Loctite Hysol $\AA 9514$ & $52 \div 53$ & $4.8 \div 5.7$ \\
(Loctite Hysol $\AA 9466)$ & $30 \div 39$ & $0.6 \div 0.8$ \\
\hline
\end{tabular}

All the adhesives showed cohesive type failures, resulting in very high strength and capacity of energy absorption. However, Hysol 9514 was found much better especially in terms of peel strength: the increase, with respect to the other adhesives, is from $300 \%$ up to $400 \%$.

However, Hysol 9466 was not used being much more brittle, even with respect to Multibond 330.

\section{Design of adhesively bonded energy absorbing columns and structural improvements}

Several design configurations for bonded square boxes are possible. Figure 1 collects some possible configurations. Fay and Suthurst [4] examined even more possibilities.

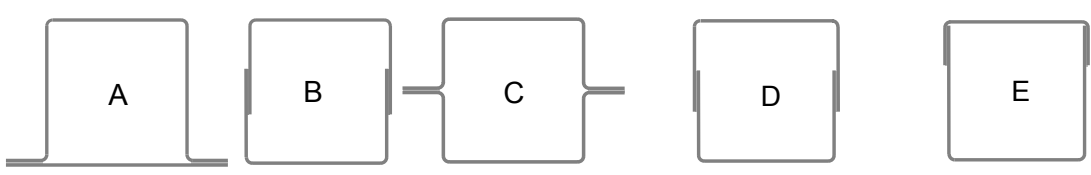

Figure 1: Different configurations for bonded square boxes.

Configuration $\mathrm{A}$ is the classical top-hat solution used in many car components. In adhesively bonded constructions it has the disadvantage of generating peel loads between the flanges. Configuration $\mathrm{C}$ is another solution used with classical spot-welds. Configurations B, D, and E are more suitable for bonding, since an opening load will stress the joint in shear, with reduced peeling.

However, both configurations D and E need to construct two different parts. On the contrary, configuration B is made of two identical parts.

Side of the square section was $40 \mathrm{~mm}$, and the total length $300 \mathrm{~mm}$. The flanges width in A and sheet superposition in B were chosen to have the same bonded area $\left(9000 \mathrm{~mm}^{2}\right)$, while maintaining the same square section.

Main objective of the successive experimental analysis was to demonstrate that bonded configuration $\mathrm{A}$ (which was chosen instead of $\mathrm{C}$ being more widely 
used) give results comparable with those obtained with bonded configuration $\mathrm{B}$. As a matter of fact configurations $\mathrm{A}$ and $\mathrm{C}$ are preferable for many reasons: they impose less changes in production lines and designers practice, adhesive application is simpler and it is compatible with the use of other spot fasteners (spot-welds, rivets, clinching etc.) in hybrid joints.

\section{Experimental tests}

A series of experimental tests in axial compression was performed on the bonded square box columns. Some quasi-static and dynamic impact tests were performed. Even if the chart will show results of single, representative tests, several repetitions were done for each case.

\subsection{Quasi-static tests}

Quasi-static tests were performed by means of a general purpose hydraulic material testing machine (DARTEC HA100, $100 \mathrm{kN}$ maximum load, $100 \mathrm{~mm} / \mathrm{s}$ maximum speed). Both solutions performed quite satisfactorily (figure 2). However, due to the inferior peel strength, some problems of debonding were encountered with Multibond 330 in configuration A. This caused a 30\% energy absorption reduction. By triggering the initial collapse phase by means of a series of transverse holes at the top of the column, this problem was avoided: the difference was then reduced to some small percent.
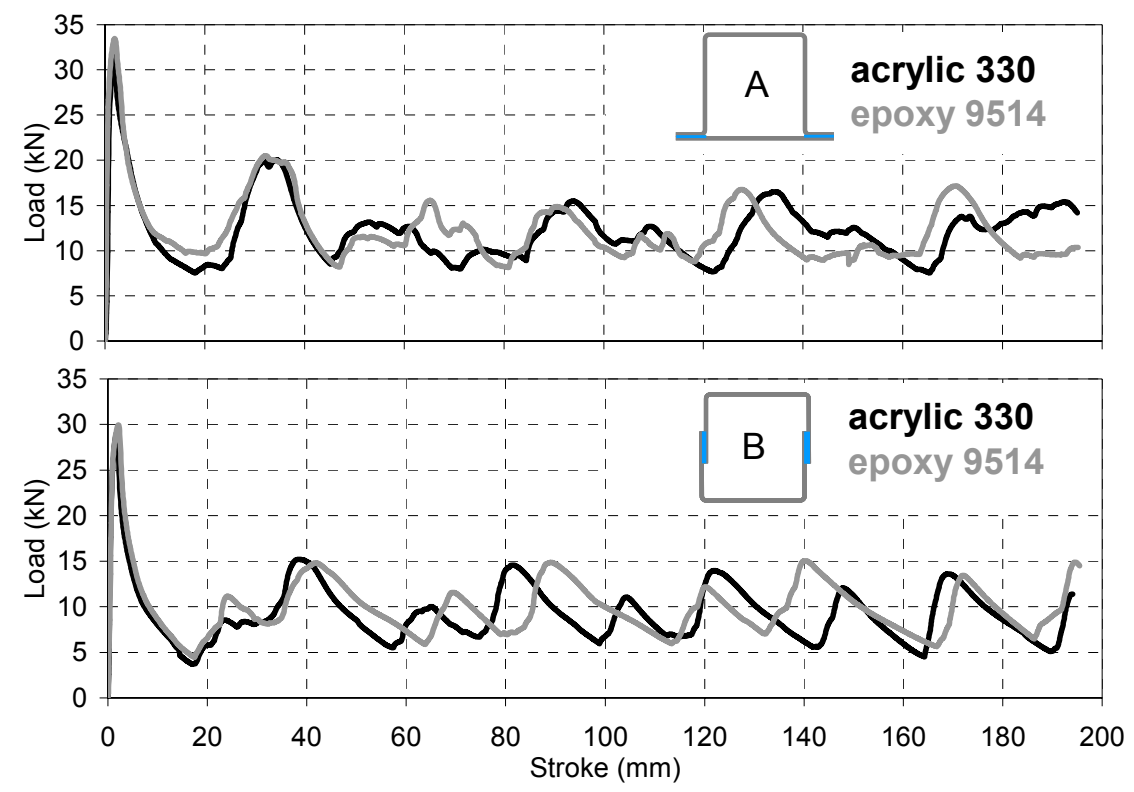

Figure 2: Quasi-static tests comparison, load-stroke curves for the two configurations and adhesives. 
Configuration B suffered, unexpectedly, of a similar problem. The reduction was however far less than for configuration A. Triggering gave improvement in efficiency for this solution too.

The final result was that almost no difference was found in the two configurations, with both adhesives. Avoiding debonding, the crash boxes behave very well in quasi-static compression, with very regular folding pattern, as shown in figure 3 .
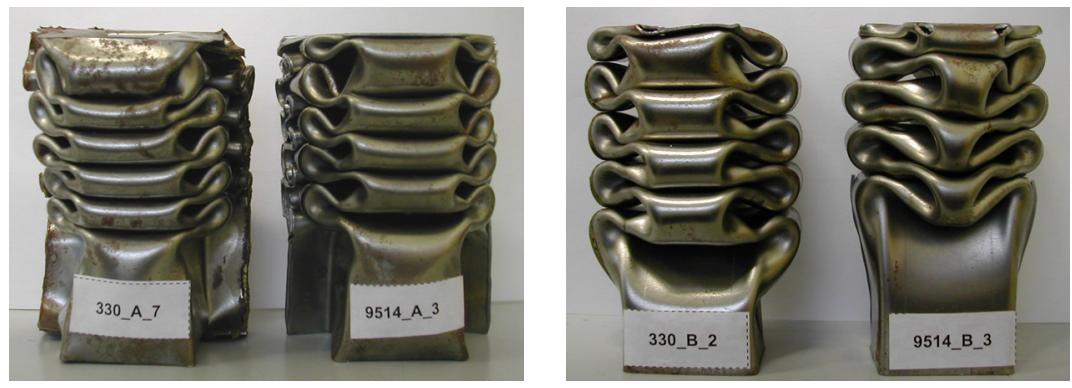

Figure 3: Folding pattern in quasi-static tests on bonded crash box columns.

\subsection{Impact tests}

Impact tests were performed with a drop tower device at the II Faculty of Engineering of Politecnico di Torino, in Vercelli. This falling weight test device [3, 8-9] has a drop height of $12 \mathrm{~m}$ and maximum speed of $13 \mathrm{~m} / \mathrm{s}$ approximately. Load is measured with three piezoelectric load cells.

The importance of triggering (figure 4) was much greater than in quasi-static tests. In some cases, with configuration A namely, transverse holes were not sufficient. Some rivets added at the top of the column helped in reducing debonding.

If debonding is avoided, the two adhesives give similar results, and the folding pattern is sufficiently regular (figure 5).

Configuration B was found less problematic, as expected. Transverse holes were sufficient to initiate a very regular folding (figure 6). It comes out that the two adhesives perform quite the same way (figure 7).

\subsection{Comparison of adhesives and influence of impact speed}

The comparison of the results found with the two analyzed configurations, and with the two adhesives, is shown in figures 7,8 and 9.

As previously mentioned, for configuration A, provided that a proper folding initialization is achieved, the two adhesives behave similarly both in quasi-static and impact conditions. Looking at the energy absorption it comes out that there is a $20 \%$ dynamic increase, mainly due to the strain-rate sensitivity of this material [8]. 

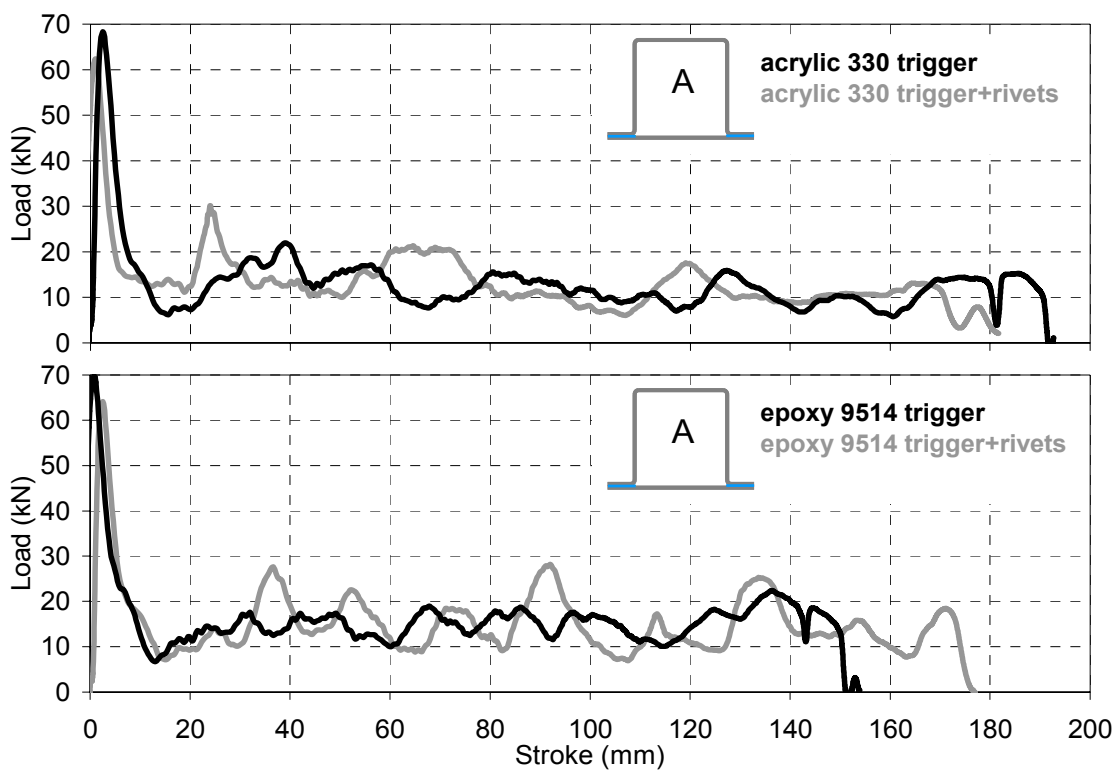

Figure 4: Comparison of the dynamic impact tests results.

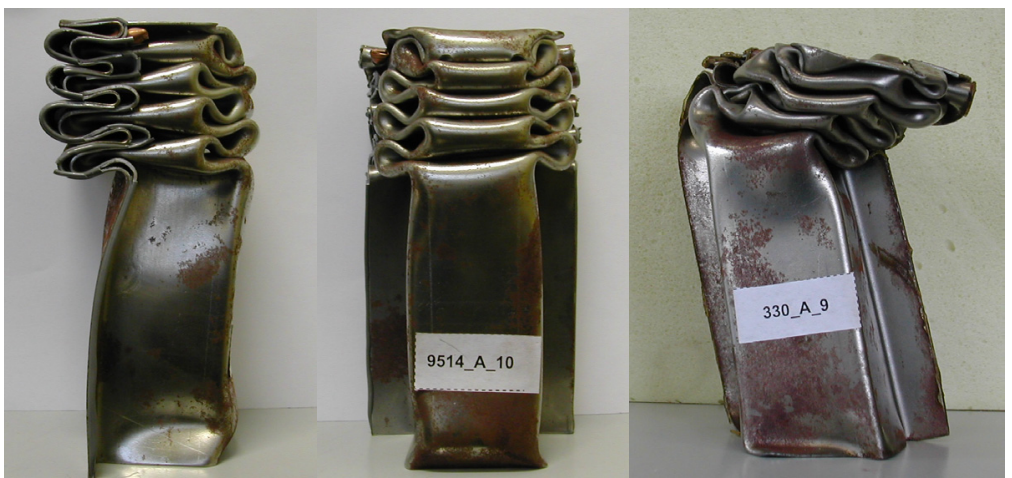

Figure 5: Dynamic, impact tests on crash box columns, configuration A, both adhesives.

Equivalent results were obtained with configuration $\mathrm{B}$. The dynamic effect, in this case, is even greater (around 35\%).

In both cases Hysol 9514 behaved better than Multibond 330 but differences are, depending on the case, of a few percent (namely, from $1 \%$ to $11 \%$ ).

\section{Conclusions}

The behaviour of square box bonded columns subjected to axial crushing was investigated. A couple of up to date high performance structural adhesives was 
used. Main objective of the work was to demonstrate the advantages of using adhesively bonded structures subjected to crash, and that very efficient structures with high capacity of energy absorption can be obtained. Moreover, this result can be obtained without particular effort in terms of preparation of the components, surface treatment, etc.

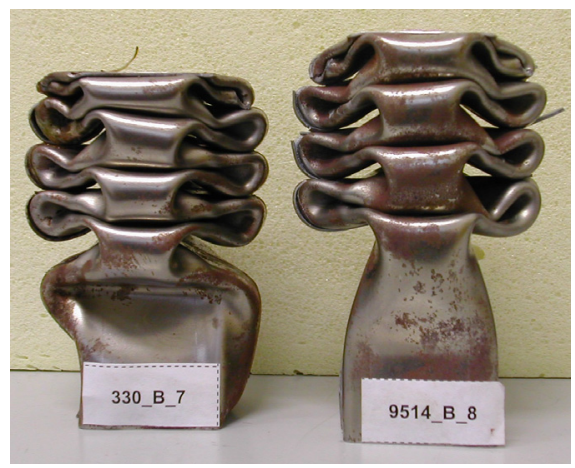

Figure 6: Dynamic, impact tests on crash box columns, configuration B, both adhesives.

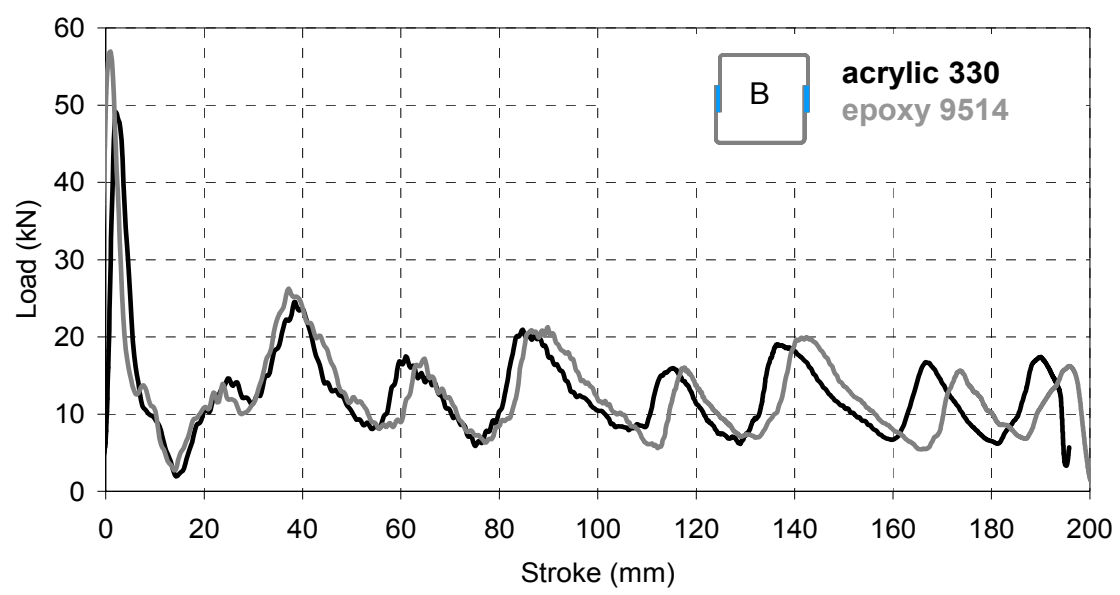

Figure 7: Comparison of the impact tests results with configuration B.

Two series of square boxes were considered: a classical top-hat section and a closed square obtained by joining two $\mathrm{C}$ shaped half-shells on the sides. When appropriate countermeasures are provided to avoid debonding, mainly by triggering and, in some cases, adding a couple of additional fasteners like rivets, the top-hat solution has more or less the same performance. This is an important practical result: for instance in car manufacturing it is not necessary to fully redesign the closed section thin walled parts of the car body. 

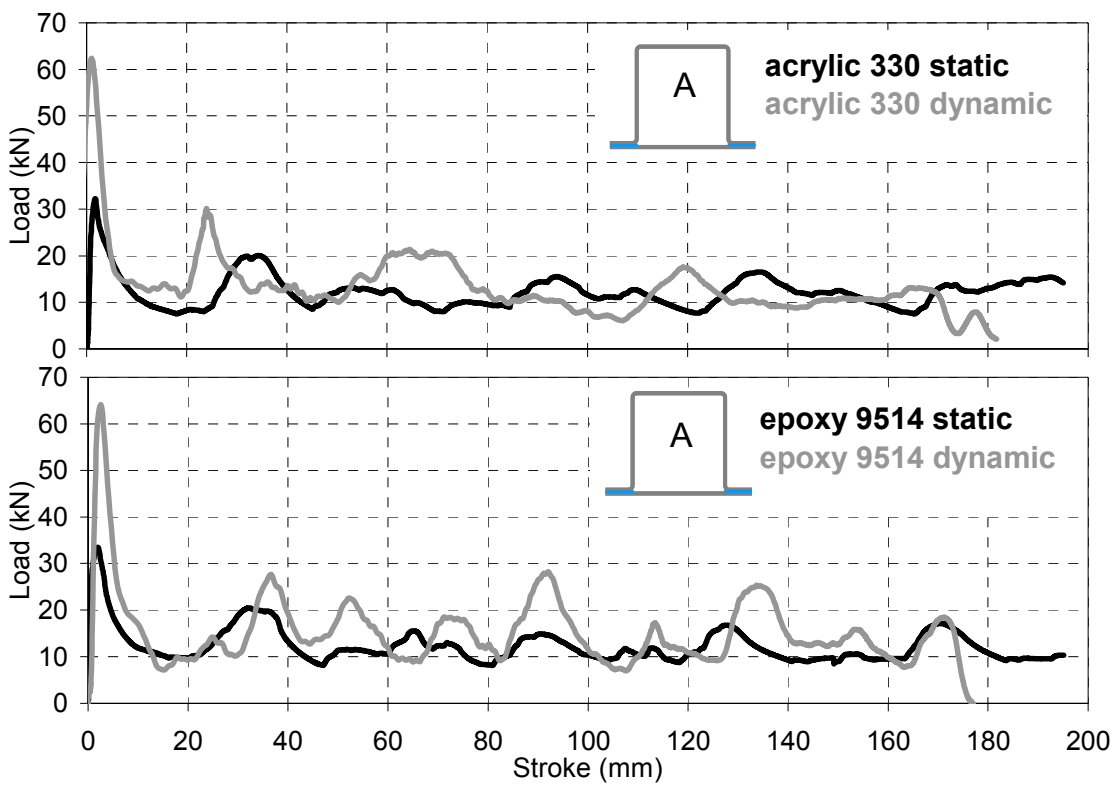

Figure 8: Comparison of the tests results for configuration A.
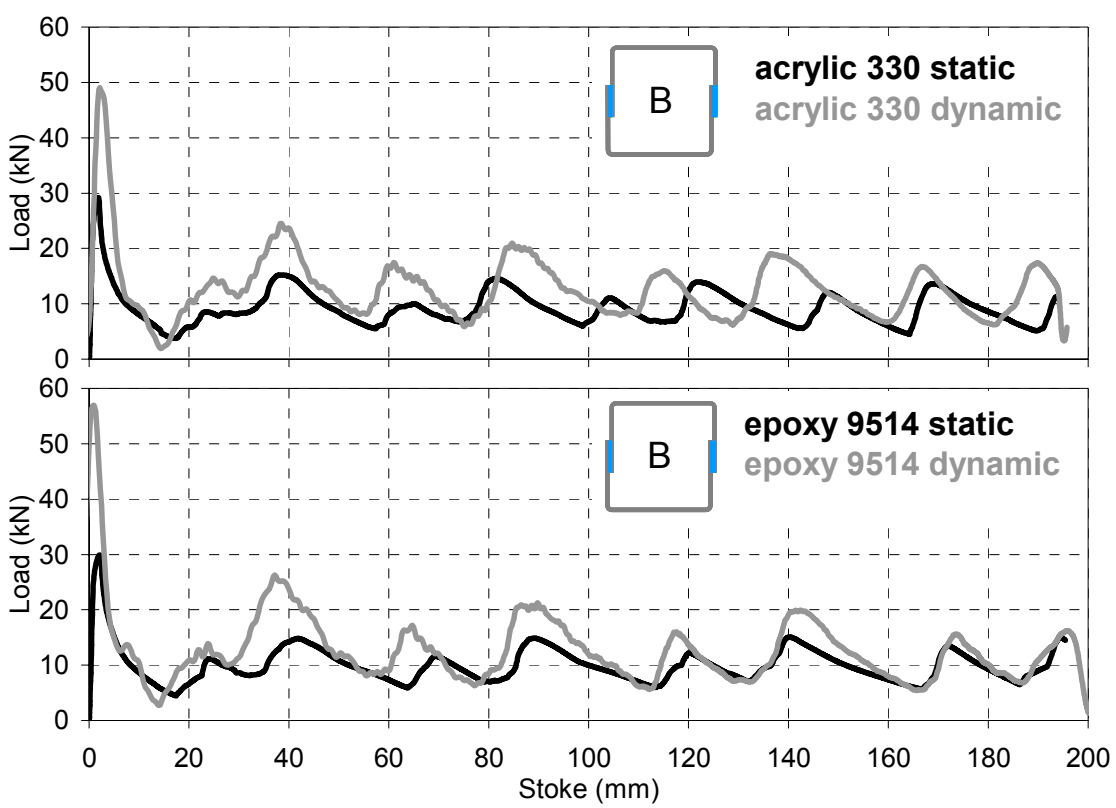

Figure 9: Comparison of the tests results for configuration B. 
At the same time, if debonding can be avoided, even a weaker adhesive can

give excellent results. The advantage lies in the fact that the adhesive gives a continuous connection of the sheets, with much more energy absorption.

Impact affects negatively the bonded column behaviour: debonding is much likely to occur, and proper countermeasures are extremely important to avoid catastrophic failure, with very little energy absorption.

\section{Acknowledgements}

The authors wish to acknowledge the everlasting enthusiastic support of Mr.

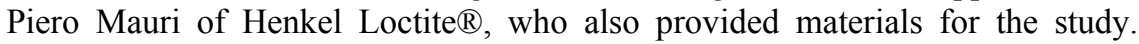
Thanks also to Alessandro Salvalaggio, for his help during the preparation of the samples and execution of the tests, and to Professor Giovanni Belingardi for his continuous support and suggestions.

\section{References}

[1] Davies, G., Materials for Automobile Bodies, Elsevier: Oxford, 2003.

[2] Belingardi, G. \& Avalle, M., Advanced materials for automotive applications. Mobility and Vehicle Mechanics, 30(2-3), pp. 51-65, 2004.

[3] Avalle, M., Experimental comparison of different innovative joining system for thin walled structures. Proc. of the ICEM12 12th Int. Conf. on Experimental Mechanics, paper No. 253, 2004.

[4] Fay, P.A. \& Suthurst, G.D., Redesign of adhesively bonded box beam sections for improved impact performance. International journal of adhesion and adhesives, 10(3), pp. 128-138, 1990.

[5] Avalle, M., Belingardi, G. \& Vadori, R., Sul collasso assiale di travi in parete sottile realizzate con adesivi: primi risultati sperimentali. Proc. of the XXX AIAS National Conference, paper No. 016, 2001.

[6] Belingardi, G., Goglio, L. \& Rossetto, M., Sul comportamento strutturale di travi scatolate con giunzioni incollate: risultati sperimentali di prove d'impatto. Proc. of the XXXI AIAS National Conf., paper No. 073, 2002.

[7] Avalle, M., Belingardi, G., Vadori, R. \& Masciocco, G., Caratterizzazione dinamica del comportamento flessionale di acciai da stampaggio. Proc. of the XXVIII AIAS National Conference, pp. 629-638, 1999.

[8] Peroni, L., Avalle, M., Petrella, V., \& Monacelli, G., Strain-rate effects on the energy absorption capability of crash boxes with different geometry. Proc. of the SUSI VII, eds. N. Jones, C.A. Brebbia \& A.M. Rajendran, pp. 259-268, 2002.

[9] Peroni, L., Evaluation of dynamic characteristic of materials by uniaxial tensile impact. Proc. of the ICEM12 12th Int. Conf. on Experimental Mechanics, ed. C. Pappalettere, McGraw-Hill: Milano, paper No. 252, 2004.

[10] Goglio, L., Peroni, L., Peroni, M. \& Rossetto, M., Caratterizzazione sperimentale in campo dinamico di un adesivo epossidico bicomponente. Proc of the XXXIV AIAS National Conference, paper No. 129, 2005. 